Supporting Information for

\title{
Access to Fluorinated Polymer Surfaces with Outstanding Mechanical Properties, High Optical Transparency, and Low Surface Energy via Nonafluoro-tert-Butyl Group Introduction
}

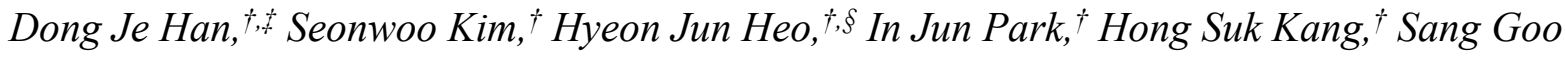
Lee,,$^{\dagger}$ Jong-Chan Lee,,$\dot{t}$ and Eun-Ho Sohn $*, \dot{\dagger}, \S$

†Interface Material and Chemical Engineering Research Center, Korea Research Institute of Chemical Technology, Daejeon 34114, Republic of Korea

\$School of Chemical and Biological Engineering, and Institute of Chemical Processes, Seoul National University, Seoul 08826, Republic of Korea

$\S$ Advanced Materials and Chemical Engineering, University of Science and Technology, Daejeon 34113, Republic of Korea

*Corresponding author: Phone: +82 $42 \quad 860$ 7943, Fax: +82 $42 \quad 860$ 7048, Email:inseh98@krict.re.kr. 
Table S1. Monomer feed ratio and chemical compositions of polymers.

\begin{tabular}{|c|c|c|c|}
\hline \multirow[b]{2}{*}{ Samples } & \multicolumn{3}{|c|}{ Chemical composition $(\mathrm{mol} \%)^{\mathrm{a}}$} \\
\hline & Feed (MMA/HEMA) & $\begin{array}{c}\text { In P(MMA-HEMA) } \\
\text { (MMA/HEMA) }\end{array}$ & $\begin{array}{c}\text { In P(MMA-NFtBEMA) } \\
\text { (MMA/NFtBEMA/HEMA) }\end{array}$ \\
\hline NFtB-5.8 & $5 / 95$ & $94.0 / 6.0$ & $94.2 / 5.8 / 0.0$ \\
\hline NFBt-9.4 & $10 / 90$ & $89.5 / 10.5$ & $90.6 / 9.4 / 0.0$ \\
\hline NFtB-19.7 & $20 / 80$ & $79.8 / 20.2$ & $80.3 / 19.7 / 0.0$ \\
\hline NFtB-38.1 & $40 / 60$ & $61.6 / 38.4$ & $61.8 / 38.1 / 0.1$ \\
\hline NFtB-57.4 & $60 / 40$ & $40.5 / 59.5$ & 42.4 / 57.4 / 0.2 \\
\hline NFtB-77.3 & $80 / 20$ & $22.3 / 77.7$ & $21.2 / 77.3 / 1.5$ \\
\hline
\end{tabular}

${ }^{a}$ Determined by ${ }^{1} \mathrm{H}$ NMR. 
Thermal Properties

(a)

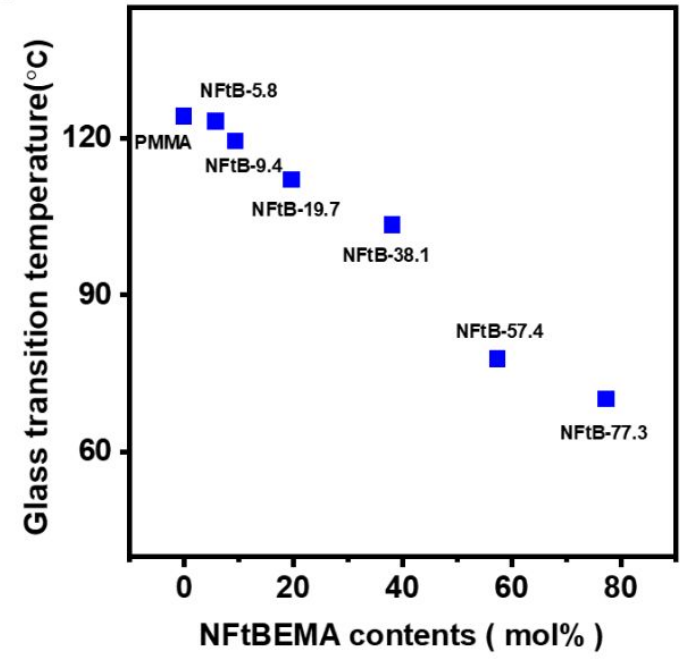

(b)

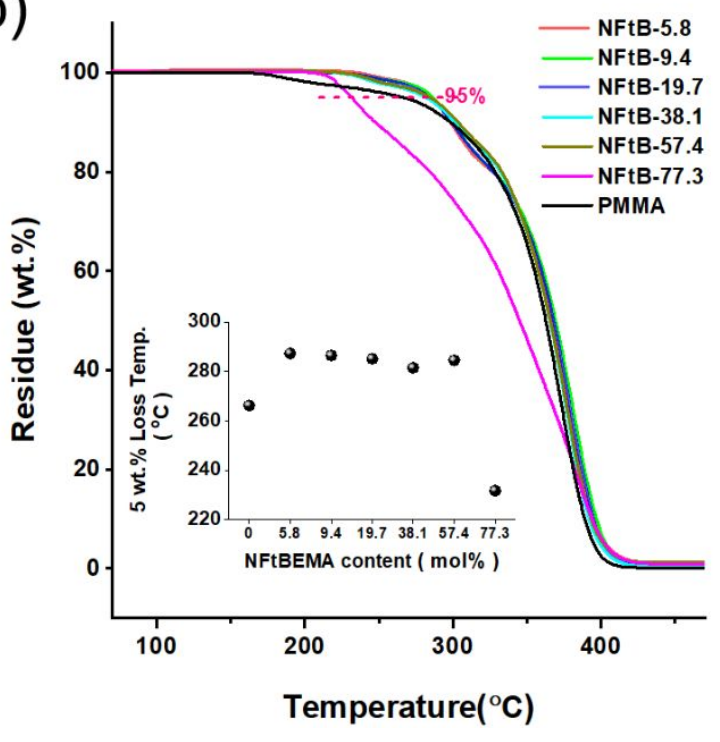

Figure S1. (a) $T_{\mathrm{g}}$ profiles and (b) TGA curves of NFtB-\#s. 
- NMR Spectra

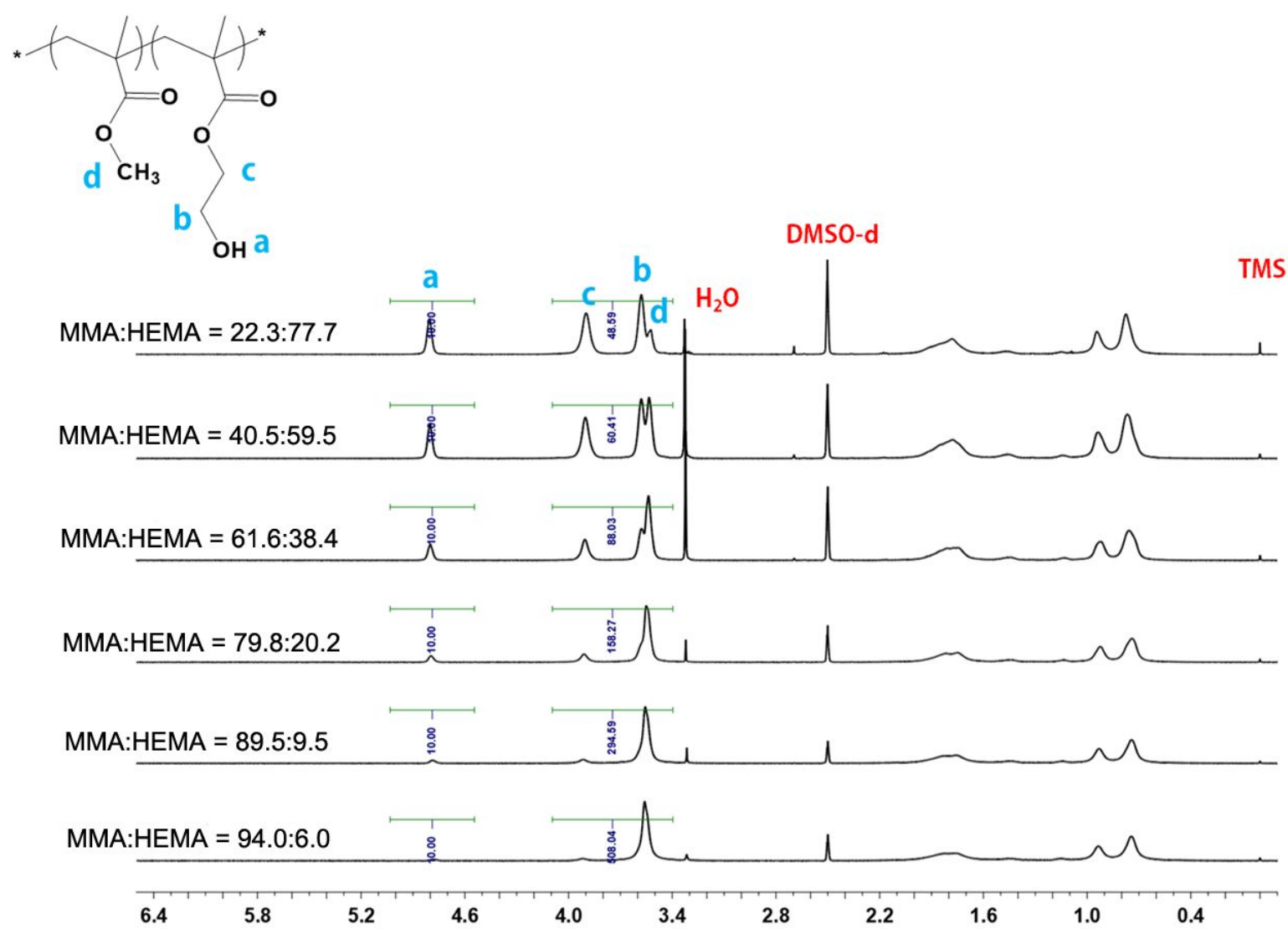

Figure S2. ${ }^{1} \mathrm{H}$ NMR spectra of P(MMA-HEMA) copolymers. 


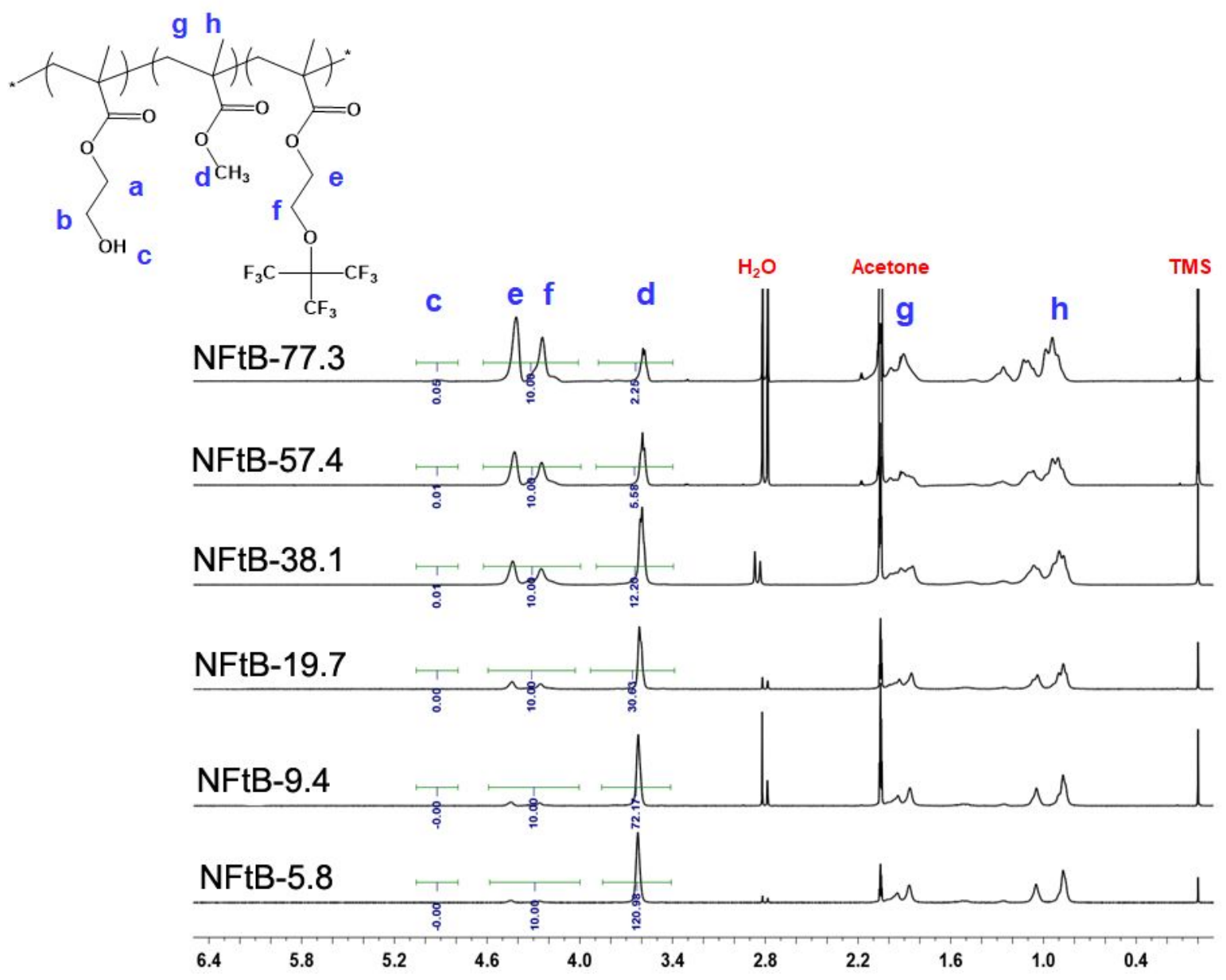

Figure S3. ${ }^{1} \mathrm{H}$ NMR spectra of NFtB-\#s. 


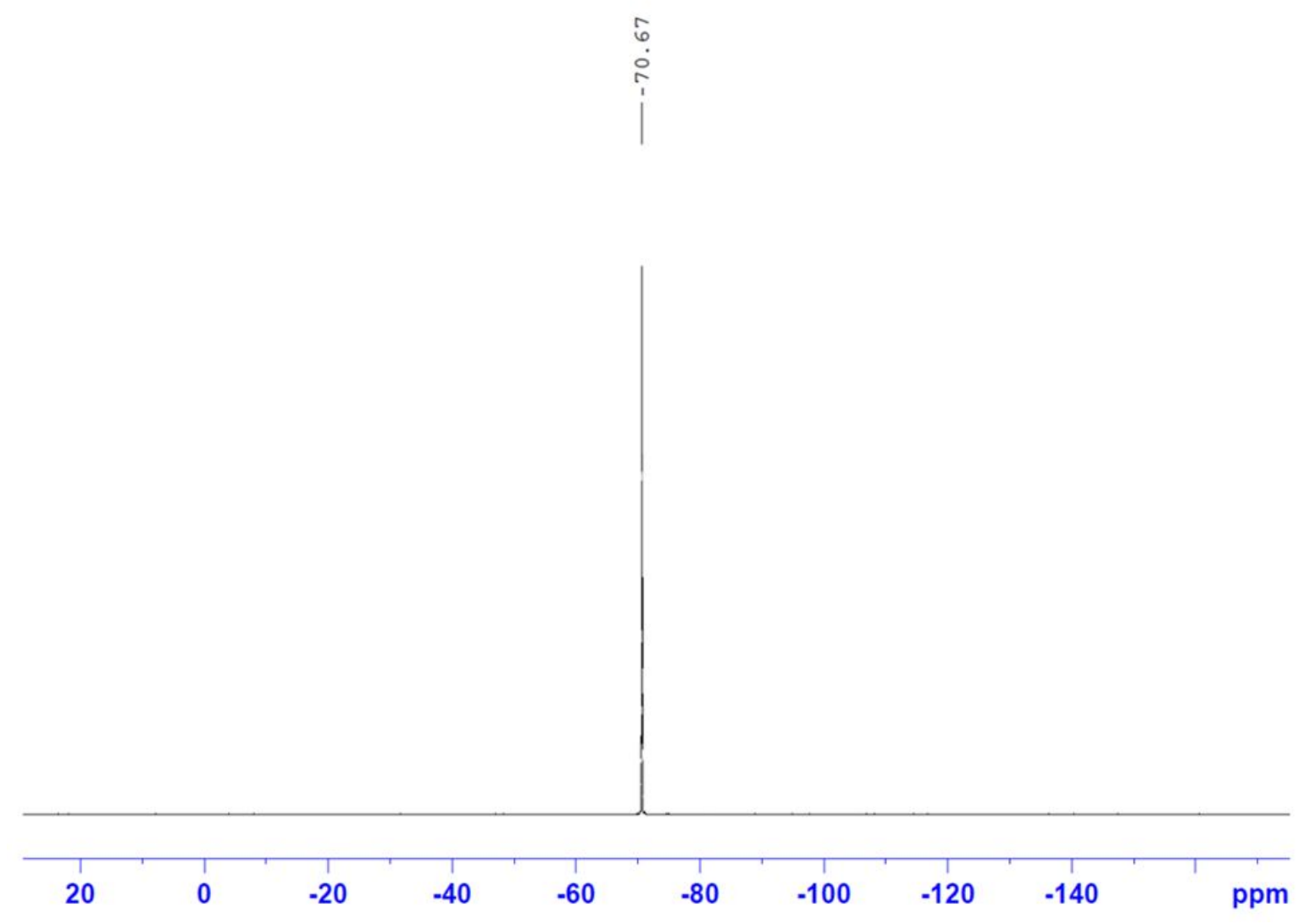

Figure S4. ${ }^{19}$ F NMR spectrum of NFtB-77.3. 
口 P(MMA-HFBMA) copolymer

(a)

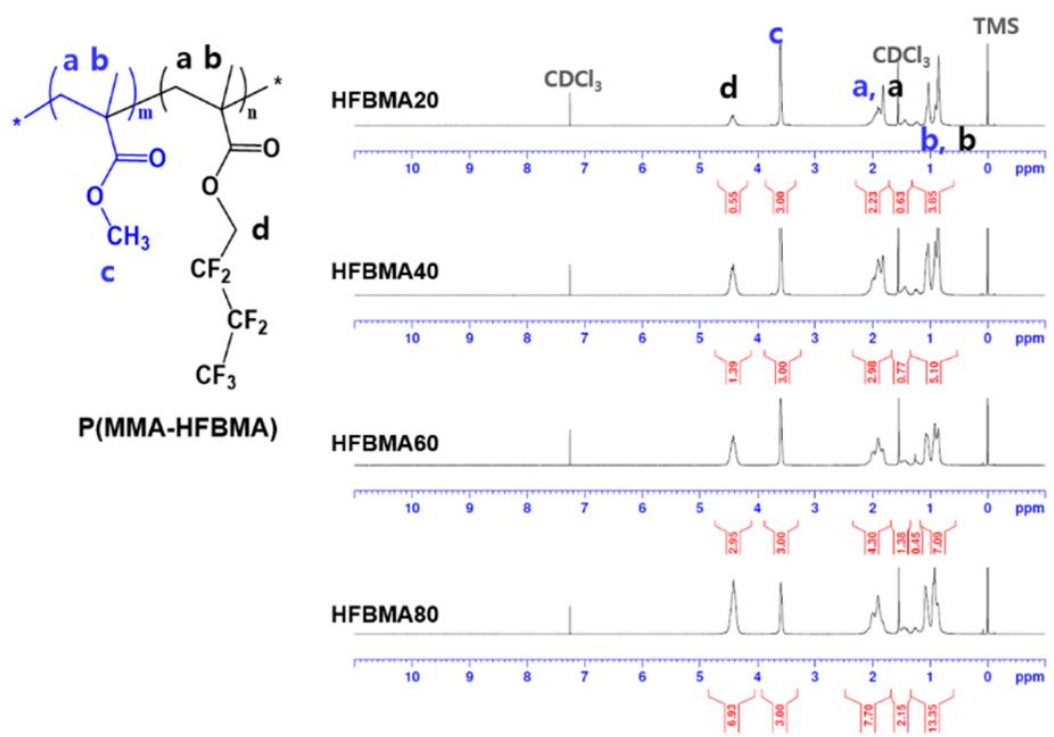

(b)

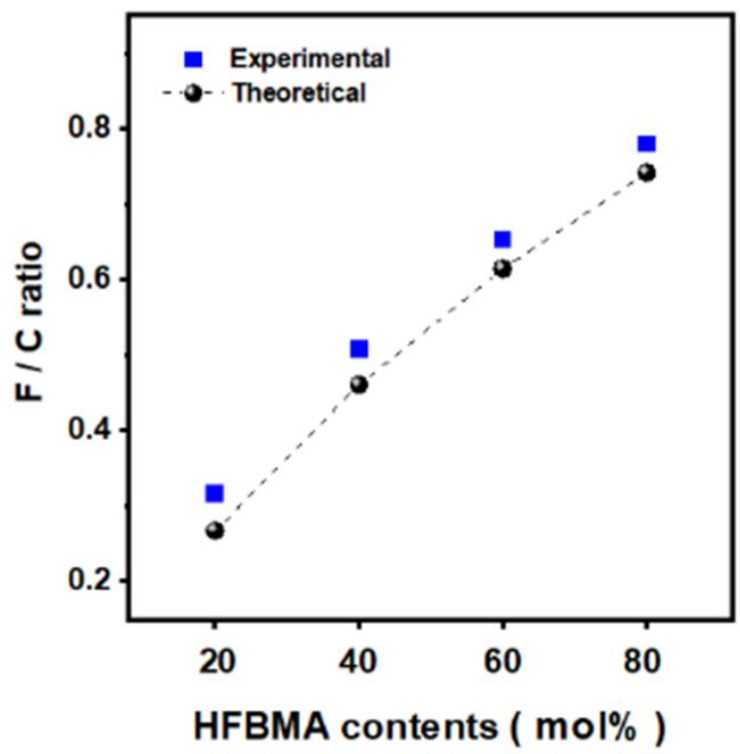

Figure S5. (a) ${ }^{1} \mathrm{H}$ NMR spectra of HFBMA-\#s and (b) Fluorine to carbon ratios on their film surfaces. 
Molecular Modelling

(a)

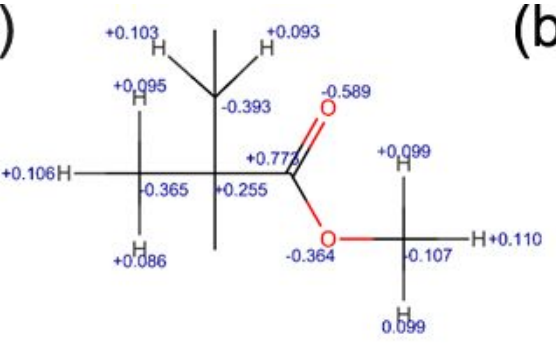

(b)

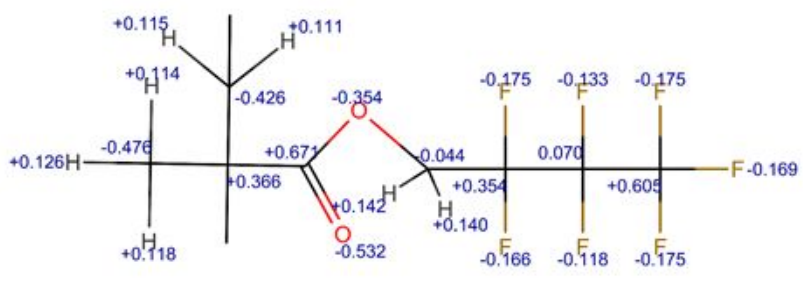

(c)

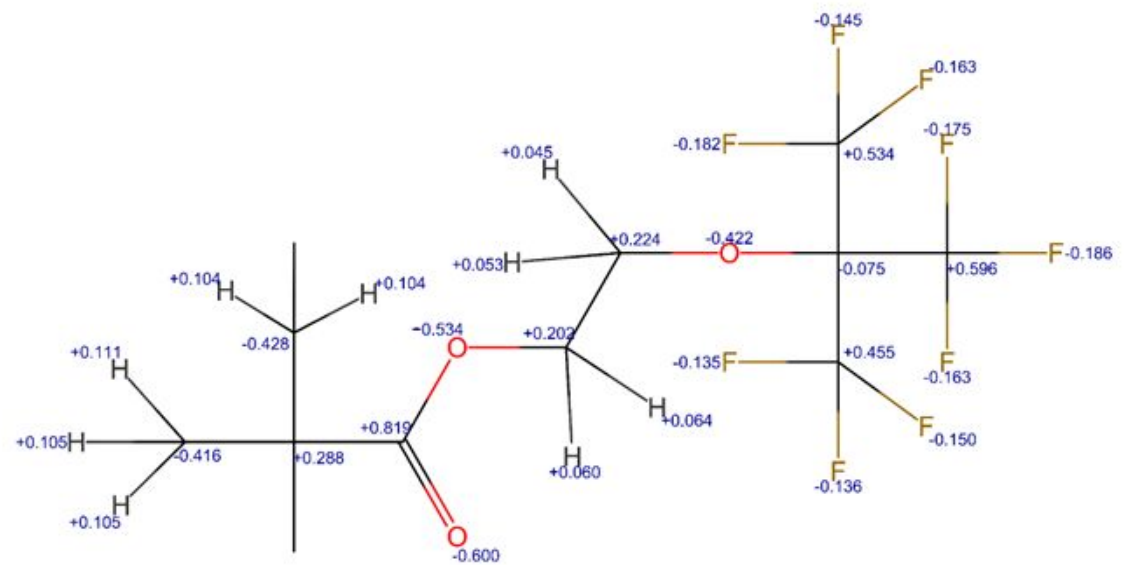

Figure S6. Merz-Kollman charge distribution of in-polymer analogues of (a) MMA, (b) HFBMA, and (c) NFtBEMA. 
(a)

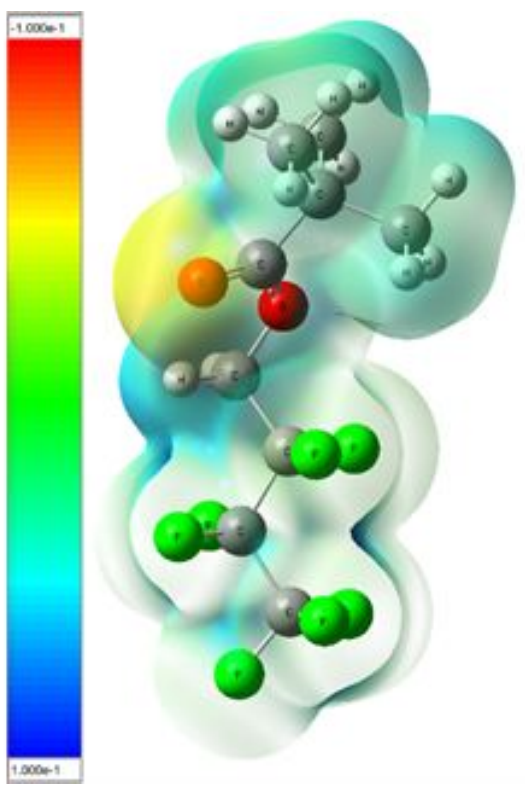

(b)

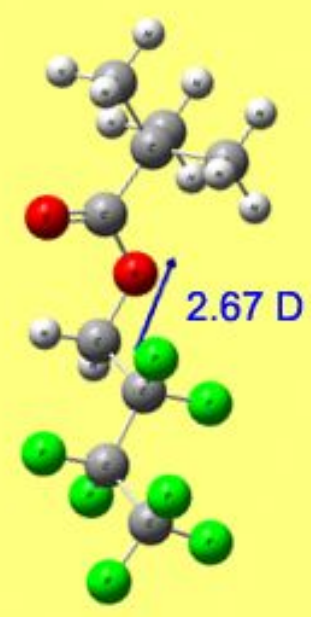

Figure S7. (a) Electrostatic potential map and (b) atomic model structure of in-polymer analogue of HFBMA (heptafluorobutyl methacrylate). (Direction of arrow in (b) indicate the direction of net dipole moment) 


\section{GIWAXD}
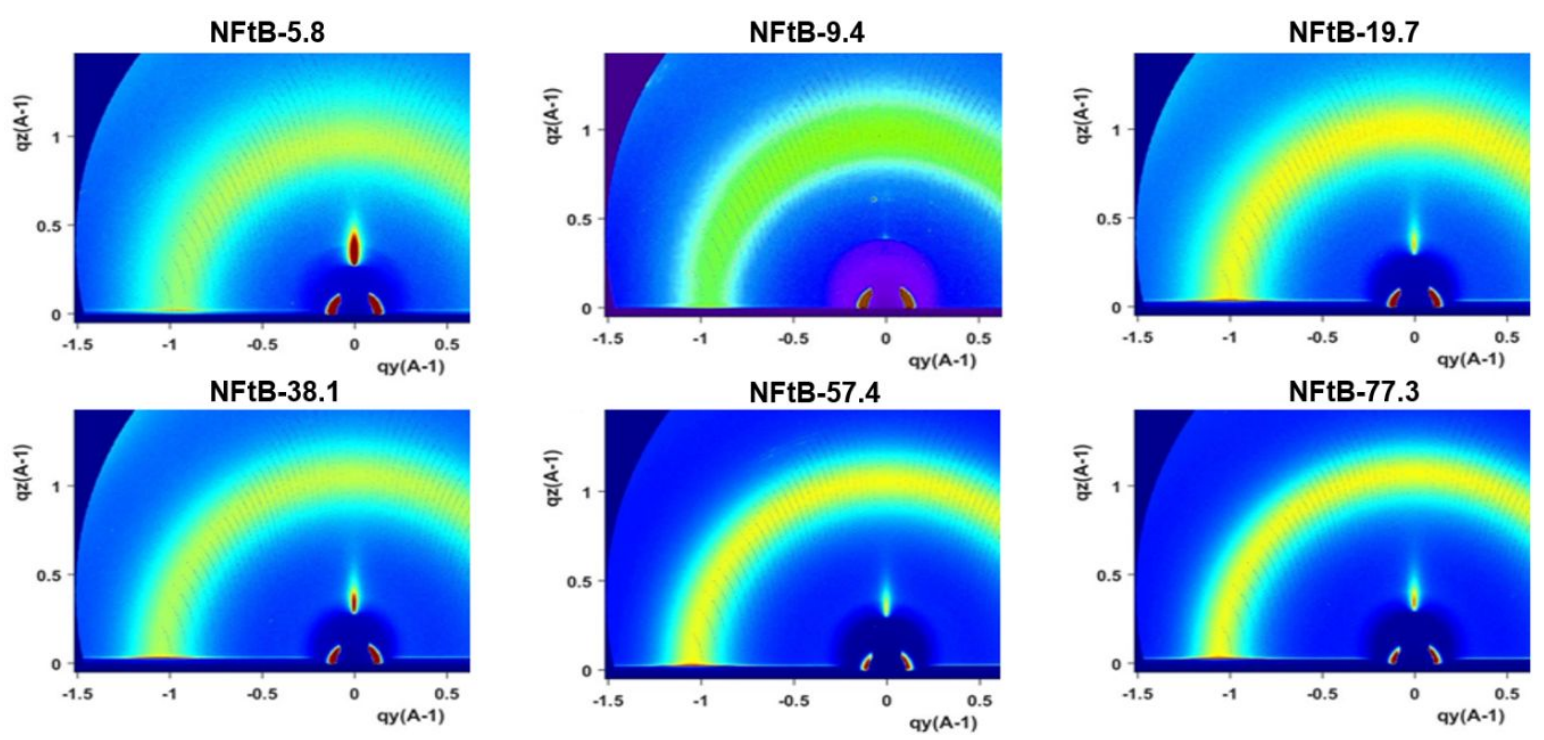

Figure S8. 2D GIWAXD diffractogram of NFtB-\#s. 
(a)

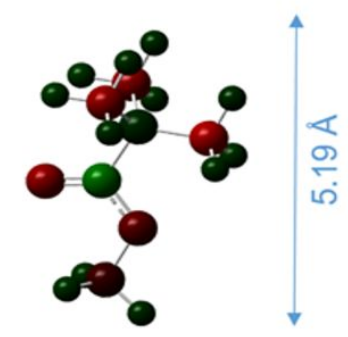

(b)

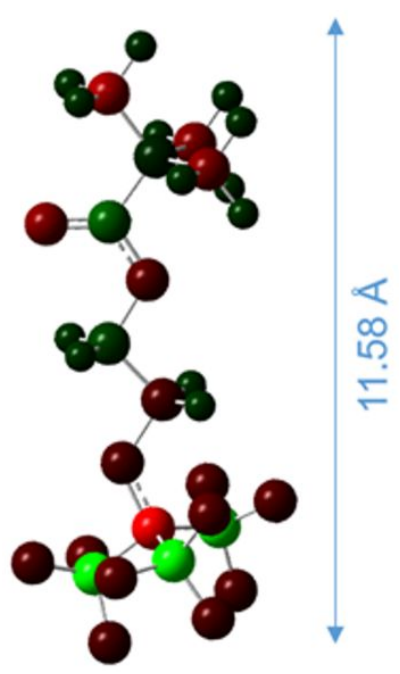

Figure S9. Molecular dimension of analogous (a) MMA and (b) NFtBEMA 


\section{- Contactc Angles}

Table S2. Contact angles and surface energies.

\begin{tabular}{ccccc}
\hline \multirow{2}{*}{ Sample } & \multicolumn{4}{c}{ Contact angle[deg.](STD) ${ }^{\mathrm{a}}$} \\
\cline { 2 - 5 } & $\theta_{\text {adv, water }}{ }^{\mathrm{b}}$ & hysteresis & $\theta_{\text {adv, dim }}{ }^{\mathrm{b}}$ & hysteresis \\
\hline NFtB-5.8 & $93.3(1.0)$ & 26.7 & $70.2(1.2)$ & 31.2 \\
NFtB-9.4 & $98.2(1.4)$ & 29.4 & $74.6(2.3)$ & 35.9 \\
NFtB-19.7 & $102.7(1.1)$ & 32.6 & $80.5(1.7)$ & 32.7 \\
NFtB-38.1 & $105.8(0.7)$ & 30.7 & $86.6(1.7)$ & 27.0 \\
NFtB-57.4 & $106.1(1.6)$ & 27.9 & $88.4(1.5)$ & 22.5 \\
NFtB-77.3 & $107.4(0.8)$ & 26.5 & $90.8(2.9)$ & 20.6 \\
\hline
\end{tabular}

${ }^{a}$ The standard deviations are indicated in parentheses.

${ }^{\mathrm{b} A d v a n c i n g ~ c o n t a c t}$ angle. 